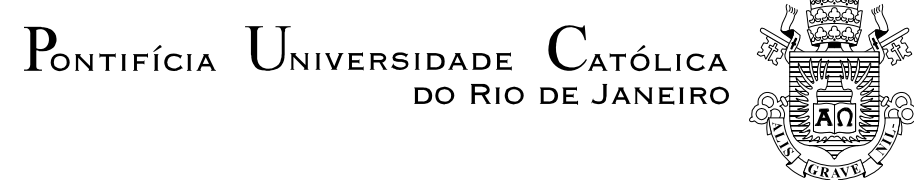

Larissa Pinha de Oliveira

Parâmetros Hermenêuticos da Mutação Constitucional

Dissertação de Mestrado

Dissertação apresentada ao Programa de Pós-graduação em Direito da PUCRio como requisito parcial para obtenção do título de Mestre em Direito.

Orientadora: Profa. Ana Lucia de Lyra Tavares

Rio de Janeiro

Fevereiro de 2011 
Pontifícia Universidade Católica DO RIO DE JANEIRO

\section{Larissa Pinha de Oliveira}

Parâmetros Hermenêuticos da Mutação Constitucional

Dissertação apresentada como requisito parcial para obtenção do título de Mestre pelo Programa de Pós-graduação em Direito do Departamento de Direito da PUC-Rio. Aprovada pela Comissão Examinadora abaixo assinada.

Profa. Ana Lúcia de Lyra Tavares

Orientadora

Departamento de Direito - PUC-Rio

Prof. José Ribas Vieira

Departamento de Direito - PUC-Rio

Prof. Paulo Braga Galvão

UERJ

Profa. Mônica Herz

Vice-Decana de Pós-Graduação do Centro de

Ciências Sociais - PUC-Rio

Rio de Janeiro, 28 de fevereiro de 2011. 
Todos os direitos reservados. É proibida a reprodução total ou parcial do trabalho sem autorização da universidade, da autora e do orientador.

\section{Larissa Pinha de Oliveira}

Bacharel em Direito pela Pontifícia Universidade Católica do Rio de Janeiro (2006). Pós-Graduação Lato Sensu na Faculdade de Direito da Universidade de Coimbra (2004). Bolsista CAPES por desempenho acadêmico de Mestrado. Advogada.

Ficha Catalográfica

Oliveira, Larissa Pinha de

Parâmetros hermenêuticos da mutação constitucional / Larissa Pinha de Oliveira ; orientadora: Ana Lucia de Lyra Tavares. - 2011.

$143 \mathrm{f.} ; 30 \mathrm{~cm}$

Dissertação (mestrado)-Pontifícia Universidade Católica do Rio de Janeiro, Departamento de Direito, 2011.

Inclui bibliografia

1. Direito - Teses. 2. Mutação constitucional. 3. Protagonismo judicial. 4. Hermenêutica filosófica. 5. Antidiscricionariedade. 6. Integridade. 7. Diálogo constitucional. I. Tavares, Ana Lucia de Lyra. II. Pontifícia Universidade Católica do Rio de Janeiro. Departamento de Direito. III. Título. 
Ao Fábio, meu amor. 


\section{Agradecimentos}

A Deus, pelas infinitas possibilidades.

A minha orientadora, Professora Ana Lúcia de Lyra Tavares, pela inestimável colaboração e delicadeza.

Ao Professor José Ribas Vieira, pela generosidade e disposição em compartilhar o conhecimento.

À Pontifícia Universidade Católica do Rio de Janeiro, pelas oportunidades de aprendizado.

A CAPES, pelo indispensável auxílio financeiro.

Ao Anderson e a Carmen, pela gentileza e prontidão.

Aos meus colegas de turma, pelos momentos inesquecíveis.

Aos meus sogros, José Fernando e Hilda, pela acolhida.

Aos meus pais, José e Sonia, pelo carinhoso incentivo.

A Lila e Gopi, por bagunçarem as certezas. 


\section{Resumo}

Oliveira, Larissa Pinha de; Tavares, Ana Lucia de Lyra. Parâmetros Hermenêuticos da Mutação Constitucional. Rio de Janeiro, 2011. 143p. Dissertação de Mestrado - Departamento de Direito, Pontifícia Universidade Católica do Rio de Janeiro.

A presente dissertação pretende investigar na doutrina alemã dos séculos XIX e XX as origens e nuances do fenômeno da mutação constitucional, por intermédio das obras clássicas de Georg Jellinek, Hermann Heller e Konrad Hesse. Através deste exame, busca-se demonstrar a insuficiência do positivismo legalista alemão no tratamento das eventuais contradições entre a realidade e a letra da Constituição. Na transposição da temática para o horizonte brasileiro, por meio da análise dos fenômenos da constitucionalização do Direito, judicialização das relações políticas e sociais e neconstitucionalismo, almeja-se demonstrar o reforço institucional do Poder Judiciário resultante do contexto fático-normativo pós-Constituição de 1988. Esta proeminência judicial culmina em uma atuação ativista, que por vezes desborda os limites textuais da Lei Fundamental. Os votos dos Ministros Gilmar Ferreira Mendes e Eros Roberto Grau na Reclamação 4.3355/AC se impõem como modelo desta subversão. Nesta quadra, com fulcro na hermenêutica filosófica de Hans-Georg Gadamer se objetiva encontrar o instrumental teórico necessário para combater a discricionariedade e a arbitrariedade judicial, por intermédio da fixação de parâmetros, de limites hermenêuticos à mudança informal constitucional. Neste diapasão, em virtude da assunção do paradigma da intersubjetividade, próprio da hermenêutica filosófica e do Estado democrático de Direito, busca-se investir em uma concepção dialógica e intersubjetiva da mutação constitucional, onde todas as instâncias e a sociedade civil, por intermédio da interpretação, podem influir nos caminhos da mudança informal constitucional.

\section{Palavras-chave}

Mutação constitucional; protagonismo judicial; hermenêutica filosófica; antidiscricionariedade; integridade; diálogo constitucional. 


\section{Abstract}

Oliveira, Larissa Pinha de, Tavares, Ana Lucia de Lyra (Advisor). Hermeneutical parameters of Constitutional change. Rio de Janeiro, 2011. 143p. MSc. Dissertation - Departamento de Direito, Pontifícia Universidade Católica do Rio de Janeiro.

This essay intends to investigate in the German doctrine of the nineteenth and twentieth centuries, the origins and nuances of the phenomenon of constitutional change, through the classic works of Georg Jellinek, Hermann Heller and Konrad Hesse. Through this review, we seek to demonstrate the inadequacy of the German legal positivism in the treatment of contradictions between reality and the letter of the Constitution. In translating the theme to the Brazilian context, by examining the phenomena of constitutionalization of the law, judicialization of political and social relation, neoconstitutionalism, we aim to demonstrate the institutional strengthening of the Judiciary as a result of the normative-factual context after the 1988 Constitution. This judicial prominence culminates in an activist judicial role, which sometimes overflows the bounds of the Constitution text. The votes of the Ministers Gilmar Ferreira Mendes and Eros Roberto Grau in the Complaint 4.335-5/AC impose themselves as a model of subversion. Nevertheless, with focus on philosophical hermeneutics of HansGeorg Gadamer we intended to find the necessary theoretical tools to fight discretion and judicial arbitrariness, through the establishment of parameters, hermeneutical limits to constitutional change. Thus, due to the adoption of the paradigm of intersubjectivity proper of philosophical hermeneutics and the democratic rule of law, we seek to invest in an intersubjective and dialogical conception of constitutional change, where all instances and civil society, through interpretation, can influence the paths of informal constitutional change.

\section{Keywords}

Constitutional change; judicial protagonism; philosophical hermeneutics; antidiscretion; integrity; constitutional dialogue. 


\section{Sumário}

1. Introdução 11

1.1. Apresentação do tema 11

1.2. Objetivos 14

1.3. Marco teórico e metodologia 15

1.4. Estrutura do trabalho 16

2. Do referencial teórico alemão da mutação constitucional ao cenário 18 brasileiro pós-Constituição de 1988

2.1. Jellinek e a mutação constitucional enquanto fenômeno empírico 19

2.2. Heller: entre a normatividade e a normalidade 23

2.3. Konrad Hesse e a questão de limites à mutação constitucional 26

2.4. Um panorama sobre o Brasil pós-Constituição de 1988: constitucionalização, judicialização e neoconstitucionalismo 33

2.5. O cenário contemporâneo: a proeminência da interpretação judicial no contexto brasileiro da mutação constitucional

3. A problemática da mutação via interpretação judicial: a crítica à discricionariedade interpretativa do Judiciário feita pela hermenêutica filosófica

3.1. A ruptura com a filosofia da consciência e a superação do esquema sujeito-objeto: a relevância da intersubjetividade no paradigma do Estado Democrático de Direito.

3.2. Da necessária unidade do ato de interpretar e compreender.

3.3. Por uma compreensão do texto enquanto evento: a impossibilidade da dicotomia texto-norma.

3.4. A problemática da discricionariedade e a mutação constitucional: uma aposta na antidiscricionaridade judicial.

3.5. Mutação constitucional e o ativismo judicial, uma associação necessária? 
3.6. A noção de Direito como integridade, a mutação constitucional como integridade.

4. A mutação constitucional via interpretação enquanto prática dialógica

4.1. A relevância da perspectiva dialógica em tempos de paradigma da intersubjetividade.

4.2. Pela superação da dualidade radical: “todo o poder aos juízes” ou “todo o poder ao legislador”. A inadequação da deferência absoluta e a necessidade de compartilhamento do Poder.

83

4.3. Repensando o fenômeno da mutação constitucional via interpretação sob a perspectiva dialógica: a possibilidade de (re)abertura do diálogo no cenário brasileiro.

4.3.1. A mutação constitucional via interpretação legislativa: a correção legislativa

4.3.2. A mutação constitucional via interpretação do Poder Executivo

4.3.3. Backlash e a mutação constitucional via interpretação popular

4.3.4. A relevância dos mecanismos formais para o diálogo social e a mudança constitucional

5. Conclusão 
Para o perfeito leitor, a palavra "árvore" não significa uma árvore: a palavra árvore é uma árvore. 